Resumo

As representações sobre as etapas da vida vêm se alterando significativamente nas últimas décadas. Em relação à infância, passa-se da ideia de infância como invenção moderna à suspeita de que estaria desaparecendo. No debate acadêmico, muitos pensam as questões implicadas nessa mudança ora aproximando ora distanciando crianças e adultos, não atentando para o que neles opera como ideal cultural: o significante jovem/juventude. Neste artigo, destaca-se certo percurso desse significante e o que ele instaura como ideal cultural, tendo em vista os dispositivos especulares que hoje definem o lugar da infancia, como o dispositivo Barbie, analisado no final deste artigo.

Descritores: jovens; infância; desenvolvimento infantil.

\section{O IDEAL CULTURAL NA DEFINICCÃO DA INFÂNCIA}

\author{
Daniel Revah
}

Æ família modernas, Ariès (1981) destaca e analisa as transformações ocorridas nas representações das "idades da vida" nas sociedades europeias, desde o final da Idade Média até o século XX. No caso da infância, o historiador francês conclui que é uma invenção moderna. Uma tese que apesar de questionada, porque a criança não teria passado tão despercebida em outras épocas e sociedades, mantém-se firme se considerarmos as particulares características que a infância adquire na modernidade, com os sentimentos e representações que Ariés analisa em seu estudo. Como etapa da vida, mal existia no medievo, pois logo que a criança adquiria alguma autonomia misturava-se aos adultos. A separação da criança do mundo adulto é uma dimensão essencial no surgimento da infância e ela ocorre de várias formas. Na iconografia, por exemplo, passa-se da representação da criança como adulto em miniatura a figuras de crianças com traços reais, além dela surgir em retratos sozinha ou como figura central em re-

Professor do Departamento de Educação da Universidade Federal de São Paulo (campus Guarulhos). 
tratos de família. Há mudanças nas roupas, com trajes específicos para as crianças, os jogos também são diferenciados, leituras são proibidas e passa-se a ter um cuidado cada vez maior com sua educação. É o período em que também se constitui a escola moderna como instituição que separa a infância por períodos cada vez mais prolongados. Surgem ainda sentimentos novos. Na família, que também se transforma, os adultos deleitam-se com a criança, que é cada vez mais "paparicada" e cuidada. Mas esses cuidados, sob o olhar dos moralistas, resultam em um crescente disciplinamento da infância, sobretudo na escola.

Poucas décadas após a publicação da investigação de Ariès, quando as suas teses ainda estavam sendo debatidas e aprofundadas, surge a ideia de que a infância estaria desaparecendo, como afirma Postman (1999) na década de 1980. Criam-se então as figuras da criança-adulto e do adulto-criança para tratar dessa mudança. E elas acabam se impondo como marcos de certas representações contemporâneas. Uma delas é a ideia de que as crianças de hoje são mais espertas e desenvolvidas do que as de algumas décadas atrás, quando não existiam os computadores nem a internet. Essas crianças "sabidas" são as crianças que deixam os adultos um tanto embaraçados, especialmente diante das novas tecnologias. Para elas, o futuro parece ter construído um atalho, enquanto os adultos ainda estão tentando entender e se entender com o novo mundo tecnológico. A velha geração parece então dispensável, a sua mediação para ingressar no mundo não parece mais necessária e até atrapalha. A figura da criança-adulto ganha corpo nessa configuração e tem como contraface a figura do adulto-criança, que corresponde ao adulto que se sente em déficit em face dela e até de si próprio, como criança que já foi. É também o adulto que se aproxima e iguala às crianças, perdendo de vista o seu lugar enquanto responsável por educálas e introduzi-las nas trilhas deste mundo. ${ }^{1}$

No Brasil, nos debates acadêmicos que explícita ou implicitamente retomam essas figuras, há um elemento que nelas encontrase implicado e que dificilmente emerge para ser interrogado: o significante jovem/juventude, que está como que embutido no hífen que as cria. Este artigo pretende trabalhar sobre esse recalque retomando certo percurso desse significante e do ideal cultural que ele institui, ideal esse consubstanciado em dispositivos especulares que definem o lugar da infância. A intenção é avançar no entendimento da natureza e procedência desses dispositivos e explicitar o que ne- 
les opera como ideal cultural. Para tanto, fechando este artigo, pretendese indicar alguns traços de um desses dispositivos especulares: o dispositivo Barbie.

\section{O Jovem como Ideal cultural}

A emergência juvenil que ocorre na década de 1960, quando estudantes universitários de vários países do mundo se manifestam contestando instituições e valores de diferentes ordens, é o que está na raiz do (re)ordenamento discursivo que o significante jovem/juventude produz nesse período e que o transforma num significante de ressonância. ${ }^{2}$ Antecedendo essa emergência, além do aumento da população de jovens, devese assinalar a constituição da própria condição juvenil como um registro que se constitui na modernidade, mais precisamente em fins do século XIX, conforme indica Ariès (1981, pp. 2949). A juventude surge do interior da infância, dentro dessa longa etapa da vida na qual, até o século XVIII, as idades mal se distinguiam. Há primeiro o reconhecimento de uma segunda infância, de uma infância escolarizada em face de uma infância que está fora da escola. Posteriormente, na indistinção de idades que caracteriza a infância escolarizada, começa a se delinear a adolescência/juventude, conforme uma trajetória que é

350 Estilos da Clínica, 2011, 16(2), 348-367 
indissociável da divisão em classes de idade que é feita no interior da escola. O século XX é "o século da adolescência", diz Ariès, muito embora seja o significante juventude o que ele emprega para indicar o surgimento dessa referência ligada ao púbere e que não deixa de se prolongar, empurrando “a infância para trás e a maturidade para frente" (pp. 46-7).

$\mathrm{O}$ (re)ordenamento discursivo da década de 1960 é o que cria a imagem do jovem politizado e idealista que afinal se consolida, inclusive com um sentido positivo, após o refluxo do movimento estudantil e quando este já tinha se tornado inexpressivo (Abramo, 1997, p. 31). No caso do Brasil, isso ocorre nas décadas de 1980 e 1990, com a mídia tomando a dianteira na criação da figura cristalizada e inerte do jovem "anos 60 ". ${ }^{3} \mathrm{Na}$ criação dessa figura é preciso considerar vários aspectos. No caso da América Latina, não pode ser dissociada da repressão política e cultural das ditaduras militares do período, que de modo geral se estende da década de 1960 aos anos de 1980. Os questionamentos juvenis foram (re)elaborados nessas condições, num período que no Brasil corresponde ao desenvolvimento intenso da indústria cultural. Esta opera (re)elaborando as inquietações juvenis de natureza política e contracultural, apropriando-se das palavras de ordem, das músicas, roupas, estilos, devolvendo tudo isso ao circuito que lhe é próprio e que nutre o mercado de consumo de massas.
No Brasil da década de 1980, já sob o impacto do refluxo do movimento estudantil e dos chamados novos movimentos sociais que desde a década anterior alcançam um primeiro plano e que então iniciam o seu declínio, os grupos juvenis emergentes tendem a rechaçar a figura do jovem "anos 60", que busca transformar o mundo e que faz dele uma imagem idílica. Os punks, que constituem uma das culturas juvenis que ganha força nesse período na cidade de São Paulo e que procede da década anterior, tornam-se então uma referência importante para os jovens. À diferença das expressões anteriores, basicamente de jovens das camadas medias, os punks procedem dos setores populares. Eles constituem um dos primeiros grupos juvenis oriundos desse setor social que se expressa e adquire visibilidade em espaços públicos ou semipúblicos, inclusive servindo de inspiração a jovens oriundos das camadas médias, com é o caso dos darks, em São Paulo. ${ }^{4}$

Nesse período, que no Brasil se inicia na década de 1980, não acontecem mais grandes acontecimentos envolvendo jovens, pelo menos até inícios da década seguinte. O que então prolifera são grupos juvenis os mais diversos. Trabalhos acadêmicos voltados para o estudo dos jovens indicam que há uma grande fragmentação e heterogeneidade, com culturas juvenis bem variadas (Abramo, 1994; Almeida, 2009; Guimarães, 1997). Nesses estudos, destaca-se que 
o foco da atuação juvenil não é mais a política, pelo menos nas formas consagradas da geração anterior. Tampouco almejam criar formas de vida alternativa, como era próprio de parte da juventude da década de 1970 (Abramo, 1994, p. 147). Eles se expressam criticamente por meio de um "estilo espetacular" que trabalha a aparência, atentando para as roupas, os adereços, o corpo. A música constitui nesses grupos um elemento essencial, assim como era para as gerações das décadas anteriores. O que importa, no caso dos punks, é expressar seu descontentamento diante do mundo por meio de expressões que são agressivas e que neles fazem confluir o que a sociedade considera imundo, podre, lixo. Os punks reúnem neles próprios essas imagens para dizer, à maneira de espelhamento, que na verdade o que é podre é a sociedade. E fazem isso por meio de uma atuação, de uma encenação espetacular que se desenrola nos espaços de lazer e diversão. São contra o consumo, mas incorporam os elementos do consumo de massas na sua própria imagem, subvertendo-os, dando-lhes outro sentido. "Faça a sua música, o seu estilo, não se acomode na postura do espectador passivo" (Abramo, 1994, p. 84). Esse é o princípio que deve ser seguido para se contrapor ao que o "sistema" impõe, não propriamente para propor outra coisa. Não há nada a propor, antes trata-se de negar de maneira radical a ordem do mundo. ${ }^{5}$ 
Outros grupos juvenis se multiplicam seguindo a pista iniciada pelos punks, como os metaleiros, darks, rappers, carecas. Visíveis nas grandes cidades, esses e outros grupos juvenis continuam a se multiplicar até hoje, com diferenças mais ou menos importantes quando consideramos os diferentes estados e cidades brasileiras. No Rio, por exemplo, o que ganha visibilidade é uma cultura juvenil ligada ao funk, que remonta à década de 1970 e concerne a uma expressão musical que mantém estreita relação com a dança, nos bailes funks, e as chamadas "galeras", que com ele se confundem (Guimarães, 1997). Nessas expressões juvenis, todas elas voltadas para uma atuação que privilegia os espaços de lazer, diversão e consumo, por vezes há ingredientes que as aproximam do mundo da violência e do crime, tornando o seu viés crítico ainda mais irreconhecível. Dos grandes acontecimentos envolvendo jovens, o único desde a década de 1980 é o que se desenrola no início da década seguinte, quando do impeachment do presidente Collor, envolvendo manifestações estudantis em diversos estados brasileiros. Entretanto, essas expressões juvenis desapareceram com a mesma rapidez com que surgiram.

Desde a emergência juvenil dos "anos 60" até os dias de hoje, ocorreram transformações significativas nas representações instituídas por meio do significante-mestre jovem/juventude. Este perdeu a sua antiga ressonância, o que não quer dizer que tenha diminuído a sua força. Digamos que ressoa de um outro modo, graças a um percurso que o transformou em um ideal cultural largamente acalentado nos dias de hoje, por todas as faixas etárias.

A força desse ideal é atestada por vários autores e estudos, com diferenças quanto ao modo de entendê-lo. Há quem coloque o acento no significante adolescente/adolescência, como se observa em Calligaris (2000), que analisa esse ideal segundo uma perspectiva que se assenta em pressupostos da psicanálise. Outros, porém, focalizam o significante jovem/juventude, como Peralva (1997), que ressalta o fato do jovem ter se transformado em um modelo cultural. A sua análise, alicerçada no campo da sociologia, retoma as conclusões de autores que discutem a significativas mudanças nos marcos que costumavam delimitar as etapas da vida. É o caso, referido pela autora, do ciclo ternário: juventude, idade adulta e velhice, que não mais concerne a um percurso linear. Abramo (2005) também destaca a confusão nos marcos que tradicionalmente definiam as etapas da vida, detendo-se especialmente na transição para a idade adulta. 
Lembra a autora que certo padrão clássico tornou-se problemático, relativo a esta sequência: "deixar a escola; começar a trabalhar; sair da família de origem, casar e formar um novo lar (e ter filhos)" (idem, p. 44). Essas divisões ficaram embaralhadas. Pimenta (2007, p. 141) destaca também esse fato, lembrando que a adolescência pode ser ultrapassada por uma pessoa que, no entanto, julga retornar a ela em um momento posterior. A sensação de vaivém, inerente às representações atuais das etapas da vida, relaciona-se com o fato desses marcos terem-se tornado um tanto fluídos e desconexos ou com vínculos que não seguem um padrão.

Sobre o jovem ou a juventude como ideal cultural, a pesquisa qualitativa realizada por Pimenta (2007) na década passada apresenta algumas conclusões interessantes para avançar no entendimento da sua significação atual. A pesquisa foi realizada como pessoas do município de São Paulo que tinham entre 19 e 35 anos, de diferente gênero e condições socioeconômicas. O foco da investigação foram as representações dessas pessoas sobre o jovem/juventude e a idade adulta, tendo em vista a transição entre essas duas etapas. A representação sobre o modo como essas pessoas tendem a pensar a transição para a idade adulta surpreendeu a pesquisadora, pois constatou que ela é pensada como uma passagem direta da adolescência à idade adulta, sem passar pela juventude. Esta é concebida, 
antes de mais nada, como um "estado de espírito", "um modo de ser ideal", "um estilo de vida idealizado" (idem, p. 144). E essas pessoas preferem designar-se como "jovens adultos" ou "adultos jovens". Adolescente e adulto tendem a ficar em lados opostos, enquanto a representação do jovem perpassa os dois, o que não significa que o jovem como representação de uma etapa da vida não apareça, embora com menor relevância.

Quanto às representações do adulto, o que emerge como característica mais geral é primeiramente a responsabilidade, sobre si próprio e sobre outras pessoas, além de outras características que são destacadas, como casar, formar família, ter filhos e trabalhar (Pimenta, 2007, p. 131). Nessas representações, Pimenta constata algumas diferenças que é importante considerar e que se relacionam com a origem socioeconômica das pessoas pesquisadas. No grupo "mais favorecido economicamente", enfatiza-se a autonomia, o fato do adulto não depender de outras pessoas; sendo praticamente o inverso no segmento "menos favorecido", para o qual a definição do adulto tende a recair nas obrigações que se tem com os outros, que nesse caso concernem à família, principalmente no que se refere aos filhos (Pimenta, 2007, pp. 135-8). Nessa última representação, o adulto torna-se alguém que passa a depender da relação com a família, com as obrigações aí implicadas.

Em relação à juventude como "estado de espírito", como postura diante da vida, Pimenta destaca as práticas ligadas ao lazer e ao consumo, além de uma certa oposição em face do que é qualificado como atitudes de velho, distanciadas dessas práticas. Para ser jovem é preciso saber se divertir, aproveitar a vida (2007, pp. 146-7). Quando entendida como etapa da vida, a autora indica que a representação da juventude ora se aproxima da adolescência ora da idade adulta. O que ela destaca, porém, mantém o jovem muito mais próximo do que seria a representação do adolescente do que a do adulto, sobretudo se considerarmos a ênfase nas práticas de lazer, diversão e consumo. No adolescente, além das mudanças físicas e de comportamento, ressalta-se precisamente a dimensão lúdica e as práticas de lazer, associadas à diversão e ao prazer. Além disso, a responsabilidade enfatizada no jovem é sobre si próprio, o qual tende também a torná-lo próximo do adolescente, embora essa mesma característica não deixe de aproximá-lo do adulto, mas apenas das representações predominantes no "segmento mais favorecido economicamente, especialmente do sexo masculino", que sugerem 
precisamente "uma identidade adulta fortemente individualizada, baseada na autonomia e na capacidade de auto-gestão" (Pimenta, 2007, p. 135). Outra dimensão importante quando se pensa no jovem surge em torno da designação "jovem adulto" ou "adulto jovem". Quando se pensa no lado adulto, o que prevalece é a sua associação com o tempo de trabalho, envolvendo preocupações e outros aspectos que tendem a ganhar um sentido negativo (Pimenta, 2007, pp. 155-6). Bem diverso disso é o significado de "ser jovem", vinculado primeiramente ao tempo do lazer. Esse é o tempo em que as pessoas da pesquisa parecem encontrar o que é da ordem da sua plenitude.

Das confluências que a análise dessa pesquisa produz, nota-se que o ideal cultural realiza-se em tempos e espaços relacionados com o lazer, a diversão e o consumo. As atividades com esse sentido são precisamente as que se tornaram o eixo das expressões juvenis desde pelo menos a década de 1980, incluídas aí as expressões que guardavam ou ainda guardam algum sentido crítico em face do mundo contemporâneo. Outro ponto a destacar é que a representação do jovem enquanto ideal cultural parece ter como principal fonte os setores sociais "mais favorecidos economicamente". E esse é o setor social cujo acesso àqueles espaços é facilitado, pelo menos se pensarmos no seu potencial de consumo e no modo como esse ideal se configura vinculado à 
mídia e ao mercado de massas, que em boa parte se apropria das expressões juvenis críticas para devolvê-las inertes ao mesmo lugar. Cabe destacar também que o ideal cultural apresenta muitos traços das representações ligadas ao adolescente. De modo que o ideal cultural que o significante jovem/juventude institui, no seu percurso desde a década de 1960, concerne ao que nele parecia como que embutido.

Eis aí então o atual ideal cultural: o jovem adolescente que se realiza nos espaços de lazer, diversão e consumo, com a condição econômica necessária para usufruir de tudo o que aí emerge. Em face desse ideal, não é de estranhar o modo como muitos adolescentes e jovens se chamam entre si, na cidade de São Paulo e, ao que parece, pertencentes a setores sociais com certo poder de consumo, como as camadas médias. Eles se chamam de "velho", usado sempre no gênero masculino, mesmo entre as meninas, assim deixando à mostra certa cumplicidade, certas referências compartilhadas, mas sobretudo, talvez, o fato de estarem no lugar do ideal. ${ }^{6}$ Afinal, eles já são os "velhos", se considerarmos que outrora, num período um tanto impreciso, os velhos representavam a autoridade, o saber acumulado. Um saber hoje nas mãos desses jovens "velhos" que conhecem como ninguém os caminhos do consumo e os atalhos para alcançar o que é da ordem do ideal.

Para aprender a caminhar nessa estrada e conhecer todos os atalhos, os jovens "velhos" foram treinados desde pequeninhos, com os inúmeros dispositivos especulares que trazem o ideal como que realizado, como é o caso do dispositivo Barbie.

\section{Barbie: a eterna garotinha}

Estamos em 2010. O nosso cotidiano é invadido por uma multiplicidade de sons eletrônicos que vez por outra nos lembram, especialmente aos mais velhos, em que época vivemos ou qual é a última novidade. A chamada do celular é um deles. Os mais velhos pouco nos preocupamos com a escolha do som do celular, somos da época em que o telefone soava de uma única maneira. Não é o caso dos jovens adolescentes, que no celular guardam um mundo de escolhas: sons, músicas, imagens, frases. Para eles, é vital definir a sua identidade por meio dessas e de outras diferenças, principalmente as que estão em jogo nos âmbitos em que, supõe-se, são os 


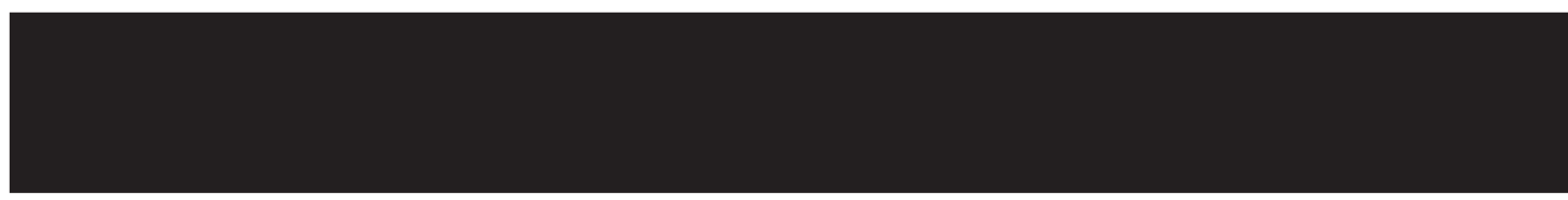

mais sabidos. É o caso de toda a parafernália eletrônica que os marca e na qual buscam criar o que é da ordem da sua singularidade, incluídas aí as grifes "da hora" e as novidades que o mercado coloca à sua disposição. O jovem adolescente "está ligado" e o celular é um de seus componentes essenciais. No celular podem ser encontrados alguns dos traços que cada jovem adolescente escolhe e cria para se diferenciar, mas também os que deixam em evidência seu lugar como jovem "velho", como representante legítimo do ideal cultural.

Eis um exemplo de uma situação vivida recentemente, quando tocou o celular da minha filha. Olhei no visor e vi: "Luuh, a eterna garotinha". Luana tem 15 anos, minha filha 16. Mais tarde fico sabendo que essa frase era usada pela própria Luana em seu celular e que "a eterna garotinha" era uma expressão da letra de um rap, de Nanaco.

Luana é mesmo uma "garotinha", uma adolescente, e a expressão que escolheu para se identificar faz pensar em certo futuro por ela almejado: ser o eterno jovem adolescente, o que não é mais do que cumprir com o mandato social de ser e permanecer no lugar do ideal cultural. Gozo ad eternum é a promessa que aí se articula, com a dimensão temporal reduzida ao presente-futuro fundidos no mesmo lugar.

A "eterna garotinha" corresponde a um ideal cultural que é acalentado desde a mais tenra idade, graças ao modo como determinados dispositivos operam sobre a infância, como é o caso do dispositivo Barbie. Transformada desde os anos $60 \mathrm{em}$ um fetiche do mundo infantil, a origem da boneca Barbie - ou, pelo menos, o que o seu fabricante divulga sobre a sua origem - é bem sugestiva a respeito do funcionamento desse dispositivo e de seu papel na criação do ideal cultural contemporâneo: "A Barbie surgiu de uma grande ideia da americana Ruth Handler que percebeu que sua filha Bárbara, cujo apelido era Barbie, gostava de brincar com bonecas de papel que trocavam de roupa. Até então, todas as bonecas tinham aparência de bebês e essa de papel era uma das únicas que tinha feição de uma adolescente ou de uma mulher adulta". ${ }^{7}$

Assim nasceu a Barbie, segundo a propaganda do fabricante, a empresa Mattel, que até hoje faz questão de lembrar o ineditismo da sua invenção: uma boneca adolescente, a primeira que não tem a aparência de um bebê. Nesse novo dispositivo há uma mudança importante em relação ao que se instaura como ideal, mas também quanto ao modo como ele opera nas mãos de uma criança. E aí é preciso considerar os inúmeros desdobramentos desse dispositivo a partir da sua forma primeira e elementar fixada pela boneca Barbie, com tudo o que foi acrescentado desde então, como os amigos da Barbie, seu namorado Ken, as bonecas étnicas e a diversidade de acessórios tornados 
imprescindíveis (roupas, móveis, casa etc.). Sem contar o universo de possibilidades aberto pelas novas tecnologias, como é o caso dos jogos à disposição das crianças pela internet, no site oficial da Barbie. Para analisar o que esse dispositivo tende a instituir nas mãos de uma criança, que, é claro, pode sempre subverter o que a forma material impõe, partiremos de algumas considerações acerca do que está implicado em toda brincadeira infantil, tendo em vista os pressupostos da psicanálise.

Quando uma criança brinca, o que ela assim (re)elabora concerne ao seu processo de estruturação subjetiva, envolvendo o complexo de Édipo e o complexo de castração. Se o processo de constituição subjetiva se desenrola mais ou menos a contento ou seja, envolvendo os inevitáveis traumas a ele inerentes - um primeiro circuito do Édipo deverá se completar na chamada primeira infância, com as instâncias e registros que desse processo resultam, seja como for que os concebamos (consciente e inconsciente; id, ego e superego; real, simbólico e imaginário etc.). Para que essas instâncias e registros se constituam, os processos de identificação que sempre estão em jogo nas brincadeiras infantis são fundamentais. Neles é possível distinguir a identificação imaginária da identificação simbólica. Essas duas formas de identificação são assim referidas por Zizek (1992, p. 104): 
a identificação imaginária é a identificação com a imagem na qual nos parecemos passíveis de ser amados, representando essa imagem 'o que gostaríamos de ser', ao passo que a identificação simbólica se efetua em relação ao próprio lugar de onde somos observados, de onde nos olhamos de modo a parecermos amáveis a nós mesmos, merecedores de amor.

Pensemos agora no que ocorre quando uma menina brinca com uma boneca-bebê. Ela fala com o bebê, troca sua roupa, lhe dá comida, o balança e realiza todo um conjunto de ações que a colocam na posição de mãe. Ela sente-se uma mãe e quer ser mãe, de acordo com o que podemos notar em inúmeras situações desse tipo. O seu próprio corpo define esse lugar, um lugar que ela delimita com seus movimentos, seus gestos, suas palavras. Desse modo, então, cria os contornos de seu futuro, com uma imagem de si mesma que, envolvendo seu corpo, tende a ficar fora do alcance da sua visão, na mesma medida em que, como mãe, projeta o seu olhar em direção ao bebê e ao cenário onde se desenrolam as suas ações e falas.

Nesse cenário a criança situa-se representando o que gostaria de ser, para se sentir amada, como sugere a perspectiva da psicanálise sobre os processos de identificação. Poderíamos pensar então na sua identificação imaginária com uma mãe, mas também com um bebê, cuidado pela figura da mãe que ela mesma representa. Sobre o lugar de onde ela pró- pria se olha para ser amada, podemos dizer que ele se configura em estreita relação com o discurso parental. Nesse discurso, porém, sempre é preciso considerar as falas nele implicadas que se articulam a partir de referências que extrapolam a sua família efetiva, sobretudo atualmente, haja vista o peso crescente da mídia, com desenhos animados e novelas que pela TV veiculam vários modelos e narrativas familiares. Sem contar o crescente direcionamento das brincadeiras infantis graças ao que se encontra inscrito na materialidade dos próprios brinquedos. Essa fala e esse olhar parental, com os quais a criança se identifica, concernem a um lugar impreciso, que lhe escapa, não sendo possível - para o próprio sujeito situá-lo de maneira unívoca.

Esse lugar impreciso corresponde ao ideal do eu, ao registro do simbólico, ao que Lacan situa no Outro. A criança faz a sua representação para esse olhar do Outro, de maneira a ajustá-la a esse olhar, a essa voz que paira em algum lugar incerto e que diz respeito ao desejo do Outro, que é o que afinal o sujeito almeja, conforme sugere a repetida frase de Lacan - o desejo do sujeito é o desejo do Outro. Ela então faz essa encenação sob o olhar do Outro e tendo em vista a melhor imagem de si mesma, o eu ideal, que corresponde ao lugar onde a criança se situa para ser amada. Mas ela sabe que é um faz de conta, que o que ela é, de acordo com o que imaginariamente concebe de si 
própria, ainda está bem distante daquela imagem desejada. $\mathrm{O}$ eu, se o entendemos como a imagem inacabada que o sujeito faz de si mesmo, não corresponde ao eu ideal, que é o que o sujeito desenha como a melhor imagem de si próprio. Uma constatação feita na infância e que perdura pela vida toda, pois o ideal do eu, que é a instância que preside aquelas duas, impede essa colagem. O ideal do eu cria uma espécie de mancha na imagem especular, de maneira que nela sempre haverá algo que estará fora de foco, mantendo vivo o desejo. ${ }^{8}$

No caso da Barbie, quando uma menina brinca com ela, a sua posição tende a mudar radicalmente, se considerarmos o que esse dispositivo a princípio incita em nosso universo cultural, que faz parte do próprio dispositivo. Agora a criança está diante de uma boneca-adolescente, de certo modo está cuidando de si mesma, do que ela será no futuro; antes ela cuidava de um filho, ou melhor, de um futuro filho; estava na posição de cuidar de um outro, impunhase essa obrigação. ${ }^{9}$ Ou então era cuidada, quando se projetava na figura do bebê, mas não sem que ela própria tivesse que assumir um outro papel, o de mãe. Ao brincar com a Barbie, penteia os cabelos da boneca-adolescente, troca sua roupa, faz ela dançar e, simultaneamente, com o mesmo movimento, ela própria está se penteando, trocando de roupa e dançando. Ao cuidar da Barbie, cuida de si mesma. A sua obrigação é consigo própria, com o cuidado da adolescente que um dia efetivamente será e que por enquanto simula ser o mais que pode, olhando a si própria na Barbie e transformando-se com todos os comportamentos e apetrechos que consiga incorporar em si mesma, apetrechos sempre disponíveis para uso imediato de qualquer criança com algum potencial de consumo. Esse afinal é o seu futuro, o lugar onde toda criança deverá se instalar para realizar o ideal cultural hegemônico. Um futuro que esse e outros dispositivos especulares, junto com a intensa demanda social que aponta no mesmo sentido, transformaram em tempo presente, incidindo até no corpo das crianças, entre as quais cada vez mais notam-se mudanças que precocemente as transformam em púberes.

A origem da Barbie, a considerar o que dela se conta, é bem sugestivo acerca do horizonte que se tornou o ideal a ser alcançado em cada momento do presente. Lembremos: Ruth Handler, casada com Elliot Handler (fundador de empresa Mattel, que produz e comercializa a Barbie), foi quem teve a ideia de fazer uma bonecaadolescente. Em relação à origem dessa inspiração, há versões dis- 
tintas. ${ }^{10}$ Uma delas é a de que a ideia teria surgido ao ver a sua filha brincar com bonecas de papel. O interessante nessa versão é que a boneca pensada com o olhar posto em sua filha -a partir de uma inspiração que podemos supor comercial, mas também tendo em vista o usufruto e o faz de conta da sua filha, que ao que tudo indica estava na adolescência -implicava fixá-la no lugar em que já se situava, no tempo presente. Para alguém como Barbara/Barbie, os cuidados dedicados a uma boneca como a desejada por sua mãe significavam cuidar de si mesma. Nessa representação, o faz de conta a instalaria em uma posição narcísica - como podemos supor ocorre hoje com muitas crianças implicadas nesse dispositivo e em outros semelhantes - e não a projetaria, ademais, em direção a um outro tempo, situado no futuro e ao mesmo tempo no passado, como é próprio do jogo simbólico, que concerne a uma dívida simbólica que se articula no discurso parental. A própria boneca Barbie, em suas várias figuras, permanece sempre na mesma idade, "congelada na idade favorita da sociedade", sem que seu corpo seja afetado por qualquer condição que possa tirá-la desse lugar, como a maternidade (Roveri, 2008b, p. 8). A Barbie/Bárbara é e sempre será uma adolescente.

A posição narcísica implicada no dispositivo Barbie também pode ser pensada a partir dos processos de identificação imaginário e simbólico. 
O eu ideal, nesse caso, corresponde à boneca-adolescente, que é a imagem com a qual uma menina busca se identificar para se sentir amada. Representando o que ela gostaria de ser, com toda a rede simbólica implicada na boneca e seus complementos, durante o desenrolar da brincadeira a Barbie permanece ao alcance da sua visão, digamos que o futuro está diante de seus olhos. E o lugar de onde ela se olha para ser amada remete também para si mesma, tanto mais na medida em que ela própria transforma-se em Barbie, em boneca-adolescente, envolvendo seu corpo, roupas e gestos. ${ }^{11}$ Nesse jogo de espelhos, em que a Barbie e ela própria se confundem, o que na verdade define a posição da criança é o dispositivo Barbie, com as narrativas e a gramática inerente aos discursos que a tornaram um fetiche infantil. Discursos em que o mercado-ciência define os objetos de gozo, à semelhança de uma mãe, do Outro primordial que funda a posição da (sua) criança no mundo. O mesmo mercado-mãe articula também o que é da ordem da falta, o que é da ordem do pai, com os intermináveis complementos e Barbies que sempre trazem algo "a mais" que deve ser comprado para tornar a imagem perfeita. Sem contar que a falta está inscrita no funcionamento do próprio dispositivo, pois quem é que consegue ser a Barbie? Como afirma Roveri (2008a, p. 84):

"A boneca foi transformada em pedaço de vidro refletor, um espelho no qual são revelados os vícios de quem a contempla e, ao mesmo tempo, estampadas as virtudes a serem conquistadas pela mulher".

Regulador do aparelho psíquico, na mesma medida em que se torna mãe e pai da criança tomada pela lógica inerente ao dispositivo Barbie, o mercado-ciência prolonga e multiplica seus efeitos graças a adesão maciça a determinado ideal cultural. $\mathrm{O}$ ideal que os jovens "velhos" têm de sustentar e que supostamente definem, muito embora também seja uma obra dos inúmeros dispositivos especulares que neles incidem, tanto mais operantes quanto mais recalcadas as forças políticas e sociais que deles se nutrem - uma questão que poderia ser desenvolvida interrogando a expressão mercado-ciência. Enfim, esses dispositivos especulares são os que em boa parte definem o lugar ideal que a todos - das mais diversas idades - convoca, a começar pelos jovens "velhos" e a (sua) infância, presente e "passada". 
EL IDEAL CULTURAL EN LA DEFINICIÓN DE LA INFANCLA

\section{Resumen}

En las últimas décadas ocurrieron significativas transformaciones en las representaciones sobre las etapas de la vida. En relación a la infancia, se pasa de la ideia de infancia como invención moderna a la sospecha de que estaria despareciendo. En el debate académico, muchos piensan las cuestiones implicadas en esa transformación ora aproximando ora distanciando niños y adultos, sin reparar en lo que en ellos opera como ideal cultural: el significante joven/ juventud. Este articulo destaca cierta trayectoria de ese significante y lo que él instaura como ideal cultural, teniendo en vista los dispositivos especulares que boy en día definen el lugar de la infancia, como el dispositivo Barbie, analizado al final de este artículo.

Palavras clave: jovenes; infancia; desenvolvimiento infantil.

THE CULTURAL IDEAL IN CHILDHOOD DEFINITION

\section{Abstract}

The representations about the phases of life have been changing significantly in the last decades. Concerning to children, moves from the idea of childhood as a modern invention, to the suspicion that was disappearing. At academic debates many think that the issues related to these changes, at times separating, at times bringing adults and children closer, not paying attention to what operates as a cultural ideal: the significant young/youth. This article points out a certain way of significant and what it determines as a cultural ideal, having the speculative devices in mind, that currently define the place of childhood, as the Barbie device analised at the end of this article.

Index terms: young adults; childhood; child development. 


\section{Dossiê}

\section{REFERÊNCIAS}

Abramo, H. W. (1994). Cenas juvenis: punks e darks no espetáculo urbano. São Paulo: Scritta.

Abramo, H. W. (1997). Considerações sobre a tematização social da juventude no Brasil. Revista Brasileira de Educação, 5/6 (número especial), 25-36.

Abramo, H. W. (2005). Condição juvenil no Brasil contemporâneo. In H. W. Abramo \& P.P.M. Branco, Retratos da juventude brasileira: análise de uma pesquisa nacional (pp. 37-72). São Paulo: Fundação Perseu Abramo/Instituto Cidadania.

Almeida, E. (2009). Os estudos sobre grupos juvenis: presenças e ausências. In M. P. Sposito (Org.), O estado da arte sobre juventude na pós-graduação brasileira: Educação, Ciências Sociais e Serviço Social (1999-2006) (Vol. 2, pp. 121-173). Belo Horizonte, MG: Argvmentvm.

Ariès, P. (1981). História social da criança e da família. Rio de Janeiro: Guanabara.

Calligaris, C. (2000). A adolescência. São Paulo: Publifolha.

Cardoso, I. (1999). Há uma herança de 1968 no Brasil? In M. A. Garcia. \& M. A. Vieira (Org.). Rebeldes e contestadores. 1968: Brasil, França e Alemanha (pp. 135142). São Paulo: Fundação Perseu Abramo.

Cardoso, I. (2001). Para uma crítica do presente. São Paulo: 34.

Cardoso, I. (2005). A geração dos anos de 1960: o peso de uma herança. Tempo Social. Revista de Sociologia da USP. São Paulo, 17(2), 93-107.

Guimarães, E. (1997). Juventude(s) e periferia(s) urbanas. Revista Brasileira de Educação, 5/6 (número especial), 199-208.

Lajonquière, L. (1999). Infância e ilusão (psico)pedagógica: escritos de psicanálise e educação. Rio de Janeiro: Vozes.

Peralva, A. (1997). O jovem como modelo cultural. Revista Brasileira de Educação, 5/6 (número especial), 15-24.

Pimenta, M. de M. (2007). "Ser jovem” e "ser adulto": identidades, representações e trajetórias. Tese de Doutorado, Faculdade de Filosofia, Letras e Ciências Humanas, Universidade de São Paulo, São Paulo.

Postman, N. (1999). O desaparecimento da infância. Rio de Janeiro: Graphia.

Roveri, F. T. (2008a). Barbie - Tudo o que você quer ser ... ou considerações sobre a educação de meninas. Dissertação de Mestrado. Faculdade de Educação, Universidade Estadual de Campinas, Campinas, São Paulo.

Roveri, F. T. (2008b). A boneca Barbie e a educação das meninas: um mundo de disfarces. Texto recuperado em 25 out. 2010: http://www.anped.org.br/ reunioes/30ra/trabalhos/GT23-3154-Int.pdf.

Zizek, S. (1992). Eles não sabem o que fazem: o sublime objeto da ideologia. Rio de Janeiro: Zahar. 


\section{NOTAS}

1 Esse problema já foi apontado e discutido por Hannah Arendt (1988) em seus ensaios sobre a crise na educação. Em autores que discutem as questões da educação a partir da psicanálise, como Lajonquière (1999), essa questão também é objeto de análise.

2 A respeito desse conceito, veja-se Revah (2004).

3 Em relação à criação dessa figura cristalizada do jovem desse período e à memória dos acontecimentos que marcaram a década de 1960, especialmente no ano de 1968, veja-se Cardoso $(1999,2001,2005)$.

4 Sobre os punks e os darks, veja-se Abramo (1994).

5 As considerações sobre os punks baseiam-se no estudo feito por Abramo (1994).

6 O uso de "velho", tanto para as meninas quanto para os meninos, corresponde também ao que parece constituir a principal fonte do ideal cultural: os homens, se considerarmos as confluências que a pesquisa de Pimenta (2007) sugere, especialmente quando se refere às representações do "segmento mais favorecido economicamente".

7 Esse trecho foi retirado de um folheto de outubro/2010 contendo propagandas de diversos brinquedos.

8 Sobre o ideal do eu como mancha, assim entendido a partir da reflexão de Zizek (1992), veja-se Revah (2004, p. 92).

9 Ser mãe não está inscrito no horizonte da Barbie, como sugere Roveri (2008a, p. 55): "Barbie não era mostrada como alguém que tinha uma árvore genealógica e seria improvável que tivesse uma prole vinculada a ela". Para a mãe da Bárbara/ Barbie, Ruth Handler, "uma gravidez jamais poderia estragar a 'boa forma física' da boneca e muito menos tirar sua auto-suficiência e liberdade" (ibidem). Roveri lembra ainda que "para contentar as crianças que queriam um bebê, Ruth criou, em 1963, a 'Barbie Babá', que vinha acompanhada de uma criança e acessórios propositadamente destinados a sublinhar que Barbie, mesmo exercendo um trabalho maternal, ainda era independente e não carregava o fardo de uma vida pósnupcial" (ibidem). Hoje as crianças já têm à sua disposição a "Barbie Pediatra", que "cuida de dois bebês e não está com roupa de médica, podendo assumir a imagem de mãe deles" (idem, p. 66).

10 Em relação a essas versões, veja-se Roveri (2008a, p. 43). Outra versão diz que, em 1956, na Suíça, Ruth Handler estava fazendo compras com sua filha adolescente e teria visto uma boneca que não conhecia - Lilli, uma garota de brinquedo alemã (idem, p. 44-5). Pensou então em se inspirar nessa boneca para produzir a da Mattel. Afirma-se também que sua filha Bárbara quis comprá-la e acabou comprando duas para a menina e uma para ela própria (ibidem).

11 A própria Mattel participa nessa transformação com seus particulares complementos: "Em 1992, um exemplar da boneca Barbie era lançado com um conjunto de maquiagem para a menina. Hoje artigos como sabonetes, perfumes, ba- 


\section{Dossiê}

tons, xampus, cremes e outros recebem o emblema cor-de-rosa da boneca, contribuindo para o considerável crescimento dos índices de produção e venda de produtos cosméticos destinados ao público infantil" (Roveri, 2008a, p. 87).

daniel.revah@unifesp.br

Recebido em maio/ 2011. Aceito em julho/2011. 